\title{
intuitio
}

\section{SARTRE E A UNIDADE DA CONSCIÊNCIA: UM BREVE REGISTRO DE “A TRANSCENDÊNCIA DO EGO”}

\author{
SARTRE AND THE UNITY OF CONSCIOUSNESS: A BRIEF \\ RECORD OF "THE TRANSCENDENCE OF THE EGO"
}

Marivania Cristina Bocca'

Claudinei Aparecido de Freitas da Silva ${ }^{2}$

Resumo: Nesse artigo, pretendemos discutir os pressupostos radicados em A Transcendência do Ego premissas a partir das quais Sartre expõe a sua tese corolariamente - fenomenológica - de um ego transcendente. Ao advogá-la, o filósofo se vale de duas críticas recíprocas: a primeira visa refutar a ideia de um ego formal que estaria contido na consciência (posição assumida por Kant e por Husserl). A segunda se contrapõe à existência de um ego material também residente na consciência (posição adotada pela psicologia clássica). Ora, Sartre reconfigura a doutrina husserliana da intencionalidade à medida que inexiste um Eu Puro como resíduo fenomenológico obtido pela epoqué, mas um cogito pré-reflexivo como condição do cogito cartesiano. Toda consciência posicional de objeto é, necessariamente, consciência não-posicional de si. Isso porque a essência mesma da consciência intencional é pura leveza, puro fluxo, movimento para..., para fora e não para dentro. É o movimento mais próprio de uma transcendência do ego.

Palavras-chave: Sartre. Consciência intencional. Fenomenologia. Transcendência do ego.

\footnotetext{
1 Universidade Estadual do Oeste do Paraná (UNIOESTE). ORCID: https://orcid.org/00000001-9120-7223.Email: boccamc@gmail.com

2 Universidade Estadual do Oeste do Paraná (UNIOESTE). ORCID: http://orcid.org/00000002-9321-5945
} 


\begin{abstract}
In this article, we intend to discuss the assumptions embedded in The Transcendence of the Ego the premises from Sartre exposes his thesis - phenomenological - of a transcendental ego, corollarily. By advocating it, the philosopher draws upon two reciprocal criticisms: the first aims to rebut the idea of a formal ego that would be contained in consciousness (position taken by Kant and Husserl). The second contrasts with the existence of a material ego also resident in consciousness (a position adopted by classical psychology). Therefore, Sartre reconfigures the Husserlian doctrine of intentionality as there is no being-for-itself as a phenomenological residue obtained by epoque, but a pre-reflective cogito, which is the condition of the Cartesian cogito. All positional consciousness of an object is, necessarily, non-positional consciousness of self. This is because the very essence of intentional consciousness is pure lightness, pure flow, movement to ..., outward rather than inward. It is the very movement of the transcendence of the ego.
\end{abstract}

Keywords: Sartre. Intentional consciousness. Phenomenology. Transcendence of the ego.

\title{
INTRODUÇÃO
}

Em A Transcendência do $\mathrm{Ego}^{3}$ (1994), Sartre afirma que, pelo princípio da intencionalidade, a consciência é relação direta com o objeto e que este se impõe a ela se agrupando com outros objetos por correlação noemática. Interessa mencionar que ${ }^{4}$, para Sartre, a intencionalidade diverge daquela proposta por Husserl. Vejamos: na fenomenologia husserliana de Ideas I (1913/2006) 5, há um "Eu" como polo unificador das vivências, logo, a intencionalidade inicia a partir do "Eu", de tal forma que o ato de conhecer encontra-se, fenomenologicamente, submetido a esse vínculo. Ou melhor, em termos husserlianos, a consciência é descrita como uma

\footnotetext{
3 O livro foi editado pioneiramente, em 1936, contando com uma reedição, em 1966, pela Vrin, de Paris. O texto que nos subsidiaremos é a tradução portuguesa de Pedro Manuel dos Santos Alves, de 1994, baseada nessa segunda edição, acompanhada, por sua vez, de uma apresentação crítica do tradutor.

4 Todas as traduções realizadas nesse artigo são de responsabilidade dos autores.

${ }_{5}$ HUSSERL, E. Idéias para uma fenomenologia pura e para uma filosofia fenomenológica: introdução geral à fenomenologia pura. Tradução de Márcio Suzuki. Aparecida do Norte: Idéias \& Letras, 2006.
} 
estrutura noético-noemática; ela integra, numa só unidade, um ato (noesis) e um respectivo correlato (noema) como polos ideais e, portanto, absolutamente, a priori. O ego transcendental é a origem de todo sentido; ele é a fonte desde onde emana as significações. Nesse modelo reflexivo, o noema é o objeto enquanto intencionado no ato; é abstrato e apesar de abstrato, não é distinto do objeto. Ainda em $/$ deas $I^{6}, \S 88$, o filósofo alemão afirma que o noema é um componente não real da consciência.

Sartre, por sua vez, reorienta criticamente esse debate teórico visando, em A Transcendência do Ego, situar a intencionalidade sob outro viés, qual seja, a de um realismo fenomenológico. O que isso significa? Significa, como nota Pedro Alves, que "o Ego se apresenta à consciência como uma unidade concreta e não como uma simples forma vazia, por outras palavras, como uma mônada"7. Em Husserl, a consciência é "pesada", monadológica. Ora, Sartre quer, ao máximo, se afastar da tese de princípio husserliana de um Eu transcendental intencionalmente unificado a título de uma consciência posicional. Fato é que a redução fenomenológica estabelecida por Husserl, nunca é perfeita. O Ego é uma “unidade noemática e não noética [...] ele só aparece quando não o olhamos [...] Ele não é visto senão pelo canto do olho"8. Esse Ego é fugidio; daí porque Sartre descreve que justamente não há necessidade de um "Eu" como polo unificador. Como Coorebyter observa, Sartre “ignora essa tendência da fenomenologia para melhor desenvolver uma visão purificada da intencionalidade que serve de antídoto ao subjetivismo" 9 husserliano.

\footnotetext{
6 HUSSERL, E. Idéias para uma fenomenologia pura e para uma filosofia fenomenológica: introdução geral à fenomenologia pura. Tradução de Márcio Suzuki. Aparecida do Norte: Idéias \& Letras, 2006.

7 ALVES, P. Irrefletido e reflexão: observações sobre uma tese de Sartre. In: SARTRE, J-P. A transcendência do ego seguido de Consciência de si e conhecimento de si. Tradução de Pedro M. S. Alves. Lisboa: Colibri, 1994, p. 37.

8 SARTRE, J-P. A transcendência do ego seguido de Consciência de si e conhecimento de si. Tradução de Pedro M. S. Alves. Lisboa: Colibri, 1994, p. 74.

9 COOREBYTER, V. Sartre face à la phénoménologie: autour de "L'Intentionnalité' et de "La Transcendence de l'Ego". Bruxelles: Ousia, 2000. p. 58.
} 
Vincent de Coorebyter ${ }^{10}$ diz que Sartre ao revisitar a fenomenologia de Husserl - "intencionalmente apresenta uma versão corrigida da fenomenologia: para que a intencionalidade coloque fim às filosofias da imanência é necessário evacuar as temáticas indissociáveis da hyle, do noema e da noese, ou seja, o avanço decisivo de Husserl em relação a Brentano". Escreve ainda Coorebyter:

Sartre prolonga e decapita o pensamento de Husserl através de um único movimento: ele negligencia [...] a fenomenologia transcendental e a multiplicidade das relações intencionais constituintes, pois elas conduzem Husserl a se aproximar das filosofias imanentistas que ele havia começado a dissolver graças ao princípio da intencionalidade entendido em seu sentido primeiro da "consciência de qualquer coisa".

Assim, a materialidade (noemática) tem função sobre o sujeito. A recusa de Sartre em relação às teses de Kant, como também às do psicologismo e às de Husserl, faz com que emerja a seguinte questão: Há lugar, em tal consciência, para um Eu? De saída, a resposta é: - Não.

Para o pensador francês, o Eu não reside em nenhum lugar na própria consciência, muito pelo contrário, o Eu não é proprietário da consciência e ele está fora da consciência, logo, encontra-se no mundo! O Eu é um existente, é um objeto transcendente do ato reflexivo ou, se se quiser, um objeto do mundo, como qualquer outro. Em última análise, a bem da verdade, nosso filósofo rejeita a posição que tanto a filosofia (idealismo ora kantiano, ora husserliano) quanto a psicologia (em particular, o psicologismo) adotam acerca da dimensão mais constitutiva da subjetividade. Afinal, trata-se de reconhecer o modo como tais posições compreendem a questão do ego e da consciência. É que, para Sartre, ambas as concepções terminam

\footnotetext{
10 COOREBYTER, V. Sartre face à la phénoménologie: autour de "L'Intentionnalité' et de "La Transcendence de l'Ego". Bruxelles: Ousia, 200o. p. 62.

"COOREBYTER, V. Sartre face à la phénoménologie: autour de "L'Intentionnalité' et de "La Transcendence de l'Ego". Bruxelles: Ousia, 2000. p. 63.
} 
por situar o ego como habitante da consciência, agindo, pois, como se a consciência fosse ora uma entidade fixa, substancial, ora, um fluxo (no caso de Husserl) que jamais se projeta para fora, isto é, para o próprio mundo.

Ser consciente de algo é estar diante da presença concreta do que não é a consciência. Logo, não faz sentido explicar a consciência conforme aquela dupla posição. Noutras palavras, em sentido radicalmente fenomenológico, inexiste ego no interior da consciência; inexiste, portanto, qualquer conteúdo, seja ele ôntico ou formal na consciência, uma vez que todo conteúdo está fora, no objeto. Por isso Sartre observa que não há necessidade de um ego transcendental como unificador dos conteúdos da consciência. Sendo o ego um objeto transcendente, ele aparece como qualquer outro que aparece no-mundo pelo ato da reflexão; logo, o ego não pode ser unificador da consciência, tampouco do mundo. Assim, em vez de um ego transcendental, o que há é a transcendência do ego. Em virtude disso emerge a questão: - O que constitui a unidade da consciência? A resposta a essa emblemática questão é, segundo Sartre, o objeto (noema).

É evidente que, quando Sartre almejou desenvolver uma investigação acerca da consciência, tomando-a como caráter fundamental de sua ontologia, ele o fez partindo da noção husserliana de intencionalidade; no entanto, vale ressaltar, que, em termos sartrianos, a intencionalidade não é apenas um aspecto da consciência à maneira de Husserl. Para o fenomenólogo francês, a intencionalidade é a própria consciência. Sartre afirma que há um único e mesmo Eu, porém, com duas faces: Je (face ativa) e Moi (face passiva). Ora, esse Eu é objeto para a consciência mesmo que a unificação das consciências seja realizada pelo objeto, que é sempre transcendente.

\section{CRÍTICAS AO EGO FORMAL E MATERIAL - DESCONSTRUÇÃO DA EXPERIÊNCIA EGOLÓGICA}

A tese fenomenológica sartriana propriamente dita parte da crítica a toda pressuposição de Ego, seja formal, num claro distanciamento de Husserl, seja material, numa contraposição radical a toda a psicologia 
empírica, como a de Brentano ou até mesmo a de Freud. Essa crítica tem os seus antecedentes em A Transcendência do Ego (1994). É nesse livro que podemos situar, em linhas gerais, a intenção do jovem Sartre em refutar a tese kantiana da existência de um Eu a priori na consciência. Pois bem, esse a priori diz respeito à estrutura do sujeito, o que, em regra, torna possível a experiência. Aqui vale retratar, mesmo que provisoriamente, as indagações, bem como as (o)posições a esse respeito do próprio Sartre em relação à forma como primeiramente Kant e, depois, Husserl conceberam o Eu.

Vejamos, primeiramente, a crítica feita por Sartre em relação ao ego a priori na consciência:

$\mathrm{Na}$ Crítica da Razão Pura (1781), a tese kantiana tem como ponto de referência a descrição das faculdades que estão presentes de forma a priori no sujeito, de modo a tornar possível o conhecimento. Immanuel Kant afirmava que, enquanto condição a priori, o Eu Penso deveria poder acompanhar as representações; mas, se o Eu, de fato, as acompanhava, isso não estava em questão, pois o que ele queria discutir era a necessidade lógica do problema e não sua constatação empírica. A Crítica de Kant se revela como um método de investigação das condições de possibilidade de a razão produzir conhecimento.

O que Kant visa compreender é se existem certas condições a priori para que as impressões sensíveis se convertam em conhecimento, logo, os seus esforços intelectuais estão todos direcionados a essa busca pelo $a$ priori. O filósofo alemão simplesmente se situou no campo da investigação transcendental. Trata-se, aos seus olhos, de “[...] desvendar as condições prévias da experiência [...] investigando a estrutura profunda, 'pré-empiricamente' válida de toda experiência, estrutura que ele - conforme o experimento da razão da revolução copernicana - presume no sujeito"12.

Tal enfoque transcendental se constituiu, para Kant, em uma revolução copernicana no interior da filosofia. O que mais lhe interessa, contudo, é descrever as faculdades que se faziam presentes (a priori) no sujeito, de

12 HOFFE, O. Immanuel Kant. Tradução de Christian Viktor Hammm e Valério Rohden. São Paulo: Martins Fontes, 2005. p. 59. 
modo a tornar possível o conhecimento. Para Kant, o transcendental era todo o conhecimento que, em geral, se ocupava com o modo de conhecimento dos objetos, na medida em que esse modo deveria ser possível a priori.

No que compete, mais especificamente, à crítica da presença formal do eu na consciência, Sartre interpreta a máxima kantiana dizendo: "Devemos concordar com Kant que o 'Eu Penso deve poder acompanhar todas as nossas representações'”'13. Para uma melhor compreensão, vejamos as palavras do próprio Kant, em seu emblemático parágrafo 16, intitulado: Da unidade originariamente sintética da apercepção, da Crítica da Razão Pura (1781), no qual afirma que,

O eu penso deve poder acompanhar todas as minhas representações; se assim não fosse, algo se representaria em mim, que não poderia, de modo algum, ser pensado, que o mesmo é dizer, que a representação ou seria impossível ou pelo menos nada seria para mim. A representação que pode ser dada antes de qualquer pensamento chama-se intuição. Portanto, todo o diverso da intuição possui uma relação necessária ao eu penso, no mesmo sujeito em que esse diverso se encontra. Esta representação, porém, é um ato da espontaneidade, isto é, não pode considerar-se pertencente à sensibilidade ${ }^{14}$.

Sartre, inicialmente, concorda com a tese kantiana, mas, na sequência, questiona a célebre premissa acerca do eu penso. Avaliemos isso mais de perto: "[...] devemos concluir daí que um Eu habita, de facto, todos os nossos estados de consciência e executa realmente a síntese suprema

\footnotetext{
13 SARTRE, J. P. A transcendência do Ego seguido de Consciência de si e conhecimento de si. Tradução de Pedro M. S. Alves. Lisboa: Colibri, 1994. p. 43.

14 KANT, I. Crítica da razão pura. Tradução de Manuela Pinto dos Santos. Lisboa: Fundação Calouste Gulbenkian, 2001. p. 157-158; B 132. Versão em PDF disponível em: http://www.verlaine. pro.br/estetica/critica_da_razao_pura.pdf. Acessado em: 08 de agosto de 2018.
} 
da nossa experiência?"15. Em resposta, o filósofo francês observa que "[...] isso seria forçar o pensamento kantiano". É importante salientar que, "[...] sendo o problema da crítica um problema de direito, Kant nada afirma sobre a existência de facto do Eu Penso" ${ }^{16}$, como sendo aquele que acompanha todos os nossos "estados de consciência", nem que ele realize a síntese da nossa experiência. Isso posto, o problema crítico é de direito e não de fato. Com efeito, o problema de Sartre com relação à existência de um Eu seja formal seja material assim se configura de maneira que os seus argumentos serão todos em prol da negação dessas duas premissas.

Na verdade, o que Sartre enfatiza com isso é que Kant teria visto “[...] perfeitamente que havia momentos de consciência sem 'Eu', pois, em sua afirmativa, o filósofo alemão destaca o 'deve poder acompanhar'”'17. Tratar-se-ia, para Kant, somente de "[...] determinar as condições de possibilidade da experiência”, e uma dessas condições é justamente “[...] que eu possa sempre considerar a minha percepção ou o meu pensamento como meu: eis tudo [...]"18, ou seja, tratar-se-ia do eu penso.

Sartre aponta para uma perigosa tendência, de que as marcas estão impressas na concepção neokantiana, no empírio-criticismo e no intelectualismo, cujos autores forçam o sentido do pensamento kantiano. O que está em jogo é apenas uma condição de possibilidade lógica ao se perguntarem sobre a "consciência transcendental", concebendo-a ora como um 'inconsciente', ora como uma 'consciência empírica'. Em discordância com esse tipo de interpretação, o fenomenólogo francês diz que, se a questão for colocada nesses termos,

\footnotetext{
15 SARTRE, J. P. A transcendência do Ego seguido de Consciência de si e conhecimento de si. Tradução de Pedro M. S. Alves. Lisboa: Colibri, 1994. p. 43- 44.

16 SARTRE, J. P. A transcendência do Ego seguido de Consciência de si e conhecimento de si. Tradução de Pedro M. S. Alves. Lisboa: Colibri, 1994. p. 43- 44.

17 KANT, I. Crítica da razão pura. Tradução de Manuela Pinto dos Santos. Lisboa: Fundação Calouste Gulbenkian, 2001. p. 157-158; B 132. Versão em PDF disponível em: http://www.verlaine. pro.br/estetica/critica_da_razao_pura.pdf. Acesso em: 08 de agosto de 2018.

18 SARTRE, J. P. A transcendência do Ego seguido de Consciência de si e conhecimento de si. Tradução de Pedro M. S. Alves. Lisboa: Colibri, 1994. p. 44.
} 
estaríamos “[...] naturalmente coagidos a conceber esta consciência - que constitui a nossa consciência empírica - como um inconsciente" ${ }^{\prime \prime 9}$.

A crítica sartriana incide sobre uma ideia neokantiana que "[...] tende a pensar como real aquilo que Kant pensou como possibilidade lógica. Por isso, a consciência transcendental aparece definida como ser"20. Ora, a discussão feita por Sartre objetiva manter a diferença estabelecida por Kant entre a consciência transcendental e a empírica, lembrando que Kant

[...] não se preocupou nunca com o modo como se constitui de facto a consciência empírica, ele não a deduziu, ao modo de um processo neo-platônico, de uma consciência superior, de uma hiper-consciência constituinte. A consciência transcendental é para ele somente o conjunto das condições necessárias para a existência de uma consciência empírica. Por conseguinte, realizar o Eu transcendental, fazer dele o companheiro inseparável de cada uma das nossas "consciências", é julgar a respeito do facto e não a respeito do direito, é colocar-se num ponto de vista radicalmente diferente do de Kant. E se, todavia, alguém pretende apoiar-se nas considerações kantianas sobre a unidade necessária à experiência, comete o mesmo erro dos que fazem da consciência transcendental um inconsciente pré-empírico ${ }^{21}$.

Se há uma distinção entre a existência de um Eu na consciência no que compete à questão de direito e a de fato e se a primeira é concedida a Kant, “[...] a questão de facto não está igualmente decidida”, restando, pois, resolvê-la. Para tanto, Sartre pergunta: “O Eu Penso deve poder acompanhar

19 SARTRE, J. P. A transcendência do Ego seguido de Consciência de si e conhecimento de si. Tradução de Pedro M. S. Alves. Lisboa: Colibri, 1994. p. 44.

20 SILVA, F. L. Ética eliteratura em Sartre: ensaios introdutórios. São Paulo: UNESP, 2004. p. 35.

${ }_{21}$ SARTRE, J. P. A transcendência do Ego seguido de Consciência de si e conhecimento de si. Tradução de Pedro M. S. Alves. Lisboa: Colibri, 1994. p. 44. 
todas as nossas representações, mas acompanha-as de fato?"22. Diante dessa complexa discussão, Sartre ainda levanta três outros questionamentos. Um deles surge quando o filósofo supõe a existência de momentos de consciência sem Eu. Se isso acontecer, resultará alguma modificação na estrutura de uma representação ou permanecerá inalterada no seu fundo? Na sequência, ele argumenta que a unidade das representações é "[...] directa ou indirectamente, realizada pelo Eu Penso - ou deve entender-se antes que as representações de uma consciência devem estar unidas e articuladas de tal modo que um 'Eu Penso' verificativo seja sempre, a seu propósito, possível?"”23. Nesse contexto, o próprio Sartre avalia essa questão reconhecendo que ela é uma questão de fato, devendo, pois, ser formulada da seguinte maneira: "O Eu que nós encontramos na nossa consciência é tornado possível pela unidade sintética das nossas representações ou é antes ele que unifica de facto as representações entre si?"24.

Para poder resolver o problema da constituição do eu penso na filosofia transcendental, Sartre afirma que o ponto de partida para a compreensão do Eu na consciência não poderia ser a tese formal do sujeito kantiano, tampouco poderia ser a encontrada “[...] nas posições dos neokantianos" 25 . Daí resulta a necessidade de se retomar a tese husserliana, embora, mais tarde, ele também refute aspectos dessa mesma tese. De qualquer forma, ele corrobora inicialmente o entendimento de Husserl no quesito do 'sujeito de fato/concreto', conforme vamos descrever a seguir.

\footnotetext{
22 SARTRE, J. P. A transcendência do Ego seguido de Consciência de si e conhecimento de si. Tradução de Pedro M. S. Alves. Lisboa: Colibri, 1994. p. 44.

${ }_{23}$ SARTRE, J. P. A transcendência do Ego seguido de Consciência de si e conhecimento de si. Tradução de Pedro M. S. Alves. Lisboa: Colibri, 1994. p. 44.

24 SARTRE, J. P. A transcendência do Ego seguido de Consciência de si e conhecimento de si. Tradução de Pedro M. S. Alves. Lisboa: Colibri, 1994. p. 45.

25 SASS, S. D. "A concepção sartriana de ego transcendental". In: Educação e Filosofia, Uberlândia, v. 13, n. 26, p. 263-274, jul./dez. 1999, p. 266. Disponível em: http://www.seer.ufu.br/index. php/EducacaoFilosofia/article/view/779. Acesso em: 12 de setembro de 2018.
} 


\section{CRÍTICA AO REVÉS HUSSERLIANO - APROXIMAÇÃO E DISTANCIAMENTO DO EGO TRANSCENDENTAL}

Podemos dizer que a proximidade de Sartre com a tese husserliana se apresenta de maneira paradoxal, pois é uma proximidade à distância. Seja como for, vejamos mais de perto isso em seus próprios termos:

[...] encontramos no caminho a fenomenologia de Husserl. A fenomenologia é um estudo científico e não crítico da consciência. O seu procedimento essencial é a intuição. A intuição, segundo Husserl, põe-nos na presença da coisa. Deve entender-se que a fenomenologia é, portanto, uma ciência de facto e que os problemas que ela põe são problemas de facto, como aliás se pode ainda perceber considerando que Husserl a denomina uma ciência descritiva ${ }^{26}$.

Vimos, conforme a afirmativa acima, que Sartre acena para uma fenomenologia husserliana enquanto uma ciência que descreve as estruturas do ego e da consciência, cujo ponto de partida é a intuição num movimento de retorno às "coisas mesmas", isto é, uma descrição das essências via a operação da epoqué. Quando Husserl opta por colocar entre parênteses a tese natural do mundo, ele refuta qualquer pressuposto transcendente. Essa postura “[...] transcendental da fenomenologia se abstém de qualquer referência à existência real do mundo objetivo ao se limitar unicamente em buscar a evidência pura"27.

Sendo assim, a fenomenologia viabilizará, para os estudos de Sartre, uma compreensão científica e não crítica acerca da consciência. Pois bem:

\footnotetext{
26 SARTRE, J. P. A transcendência do Ego seguido de Consciência de si e conhecimento de si. Tradução de Pedro M. S. Alves. Lisboa: Colibri, 1994. p. 45.

27 CONCEIÇÃO, A. A tese de Sartre sobre a transcendência do ego: a recepção crítica do método fenomenológico e as origens da ontologia fenomenológica. In: CASTRO, F. C. L.; NORBERTO, M. (Orgs.). Sartre hoje. Porto Alegre: Editora Fi, 2017. p. 254. v. 1. Disponível em: https://www.editorafi.org. Acesso em: 15 de setembro de 2018.
} 
Era isso que ele almejava. E é exatamente por a fenomenologia revelar-se uma "ciência de fato"28 que Husserl

[...] reencontra e apreende a consciência transcendental de Kant através da eroxn. Mas esta consciência já não é um conjunto de condições lógicas, é um facto absoluto. Não é já também uma hipóstase do direito, um inconsciente flutuando entre o real e o ideal. É uma consciência real, acessível a cada um de nós a partir do momento em que executa a "redução" 29.

Segundo Sartre, a fenomenologia, enquanto método de estudo, além de descrever, compreende os problemas acerca das "relações do Eu com a consciência" como "problemas existenciais"30. Logo, tal doutrina se ocupa dos fatos, ou seja, da realidade, na contramão da tese kantiana, que se ocupa apenas dessa relação, de direito. A fenomenologia descreve o eu e a consciência, sem analisá-los ou explicá-los, enquanto que a tese kantiana inventaria as possibilidades lógicas a priori ${ }^{31}$.

Em concordância com a tese husserliana, o filósofo francês diz seguir e, portanto, acreditar nas "admiráveis descrições" de seu mestre alemão, afirmando a "existência de uma consciência constituinte", bem como apontando a consciência transcendental constituindo o mundo e se aprisionando na consciência empírica. Retrata ele: “[...] estamos per-

\footnotetext{
${ }^{28}$ Franklin Leopoldo e Silva (2004) diz que Sartre esclarece que "[...] o que está chamando de ciência dos fatos é a mesma coisa, nesse caso, que Husserl denomina ciência de essências. Compreenda-se: Sartre não quer dizer que a Fenomenologia seja a ciência dos fatos empíricos, nem está, muito menos, ignorando a diferença entre fatos empíricos e essências. O que ele deseja estabelecer é que a Fenomenologia se preocupa com o que é dado na intuição, seja real, seja ideal, e não, como Kant, com as condições de possibilidade do conhecimento". In: SILVA, F. L. Ética e literatura em Sartre: ensaios introdutórios. São Paulo: UNESP, 2004. p. 36.

29 SARTRE, J. P. A transcendência do Ego seguido de Consciência de si e conhecimento de si. Tradução de Pedro M. S. Alves. Lisboa: Colibri, 1994. p. 45-46.

3o SARTRE, J. P. A transcendência do Ego seguido de Consciência de si e conhecimento de si. Tradução de Pedro M. S. Alves. Lisboa: Colibri, 1994. p. 45.

${ }_{31}$ SILVA, F. L. Ética e literatura em Sartre: ensaios introdutórios. São Paulo: UNESP, 2004.
} 
suadidos tal como ele que o nosso eu psíquico e psicofísico é um objecto transcendente que deve ficar ao alcance da $\varepsilon \pi 0 x \eta^{\prime \prime 32}$.

Apesar de tantas concordâncias com o seu mestre, fez-se necessário, para Sartre, o seguinte questionamento: - Já não seria suficiente o eu psíquico e psicofísico? "Será preciso duplicá-lo por um Eu transcendental, estrutura da consciência absoluta?" ${ }^{3}$. Vejamos que, segundo a posição sartriana, as consequências de uma resposta negativa contestam a existência de um Eu transcendental (um habitante da consciência), assim vindo a fundamentar a concepção fenomenológica impessoal da consciência transcendental sem um Eu. Ora, tais consequências não podem ser negligenciadas:

[...] 1) se o campo transcendental torna-se impessoal ou, se se prefere, "pré-pessoal", ele não tem Eu; 2) que o Eu não aparece senão ao nível da humanidade e não é senão uma face do eu, a face activa; 3) que o Eu Penso pode acompanhar todas as nossas representações porque surge sobre um fundo de unidade que ele não contribui para criar e que é esta unidade prévia que, ao contrário, o torna possível; 4) que seria lícito perguntar se a personalidade (mesmo a personalidade abstracta de um Eu) é um acompanhante necessário de uma consciência ou se se não pode conhecer consciências absolutamente impessoais ${ }^{34}$.

Vale ressaltar, como bem coloca Silva, “[...] que a expressão 'campo transcendental', utilizada por Sartre, indica a separação entre a consciência e o Eu, o que implica que a consciência é constituinte e o Eu é constituído"35.

\footnotetext{
32 SARTRE, J. P. A transcendência do Ego seguido de Consciência de si e conhecimento de si. Tradução de Pedro M. S. Alves. Lisboa: Colibri, 1994. p. 46.

33 SARTRE, J. P. A transcendência do Ego seguido de Consciência de si e conhecimento de si. Tradução de Pedro M. S. Alves. Lisboa: Colibri, 1994. p. 46.

34 SARTRE, J. P. A transcendência do Ego seguido de Consciência de si e conhecimento de si. Tradução de Pedro M. S. Alves. Lisboa: Colibri, 1994. p. 46.

35 SILVA, F. L. Ética e literatura em Sartre: ensaios introdutórios. São Paulo: UNESP, 2004. p. 37.
} 
Assim, portanto, o "campo transcendental" é definido "sem Eu". É o que aprecia também Priest quando escreve:

O campo transcendental é "liberado" pela abolição do ego como sujeito porque seu desaparecimento deixa espaço para uma descrição fenomenológica dos conteúdos da consciência como são dados, sem falsos compromissos com um ego transcendental. O campo transcendental é purificado no sentido direto de que não somos mais compelidos a acreditar que um ego aparece como parte dele. Ela recupera o que Sartre chama de "transparência". Em certo sentido, o campo transcendental não é nada, mas em certo sentido, é tudo ${ }^{36}$.

Dessa forma, a contestação de Sartre é no sentido de mostrar que é o Eu que aparecerá como um objeto psíquico transcendente e que o caráter impessoal da consciência é correlato da sua imaterialidade. Só faria sentido postular uma consciência pessoal se seu caráter estivesse pautado na materialidade. Ora, como não está, não é possível!

Uma das críticas de Sartre à tese de Husserl é que, num primeiro momento, o filósofo alemão apresenta as suas ideias elencadas nas Investigações Lógicas, onde o "[...] Eu [Moi] era uma produção sintética e transcendente da consciência ${ }^{37 "}$. Já num segundo momento responde a partir da sua fundamentação teórica das Ideias I, que presume um retorno “[...] à tese clássica de um Eu transcendental que estaria como que por detrás de cada consciência, que seria uma estrutura necessária das consciências". Sartre não compactua com a mudança no idealismo fenomenológico husserliano, ao dizer que não há razão que possa justificar a reintrodução desse Eu na consciência, uma vez que o próprio Husserl já havia recusado isso em seu primeiro momento.

\footnotetext{
${ }^{36}$ PRIEST, S. The subject in question: Sartre's critique of Husserl in The transcendence of the ego. London/New York: Routledge, 2000. p. 137.

37 SARTRE, J. P. A transcendência do Ego seguido de Consciência de si e conhecimento de si. Tradução de Pedro M. S. Alves. Lisboa: Colibri, 1994. p. 46.
} 
$\mathrm{Na}$ tentativa de entender tal mudança da perspectiva husserliana, Sartre observa que um dos argumentos utilizados para a existência de um Eu transcendental se justificaria a partir da "[...] necessidade de unidade e de individualidade da consciência [...] ora, é certo que a fenomenologia não tem necessidade de recorrer a este Eu [...]" para realizar a síntese das consciências, uma vez que a consciência se define pela intencionalidade. É que, "[...] pela intencionalidade, ela transcende-se a si mesma, ela unifica-se escapando-se $\mathrm{e}^{\prime 38}$. Sob essa perspectiva, não há compatibilidade entre a intencionalidade e a presença do Eu transcendental. Dito de outro modo, para Sartre, a fenomenologia poderia, a partir do conceito de intencionalidade, dispensar a ideia de um Eu opaco como habitante da consciência.

Vimos, até aqui, que Sartre recorreu à fenomenologia com a intenção clara de contrapor-se à necessidade de um Eu Penso que acompanhe todas as nossas representações, opondo-se, assim, à tese kantiana. Em seguida, o filosofo francês criticou a tese husserliana, opondo-se claramente ao pressuposto formal do Eu como garantia da unidade da experiência. Assim, de acordo com Coorebyter ${ }^{39}$, o projeto sartriano consistia em diagnosticar o risco da redução de um 'universo externo' para uma 'experiência interior', bem como postular que a consciência não precisa de um polo unificador que a individualize. Ocorre que, em Sartre, a experiência da consciência é desprovida de 'interior', quer dizer, ela é reduzida a 'fugir', deslizando para 'fora de si mesma'.

Sartre então conclui a sua crítica, alegando que é a consciência

[...] que torna possível a unidade e a personalidade do meu Eu. O Eu transcendental não tem, portanto, razão de ser. Mas, além disso, este Eu supérfluo é nocivo. Se ele existisse, arrancaria a consciência de si mesma, dividi-la-ia, insinuar-se-ia em cada consciência como uma lamela opaca. O Eu transcendental éa

\footnotetext{
38 SARTRE, J. P. A transcendência do Ego seguido de Consciência de si e conhecimento de si. Tradução de Pedro M. S. Alves. Lisboa: Colibri, 1994. p. 47.

39 COOREBYTER, V. Sartre face à la phénoménologie: autour de "L'Intentionnalité' et de "La Transcendence de l'Ego". Bruxelles: Ousia, 2000.
} 
morte da consciência. Com efeito, a existência da consciência é um absoluto porque a consciência está consciente dela mesma. Isto quer dizer que o tipo de existência da consciência é o de ser consciência em si. E ela toma consciência de si enquanto ela é consciência de um objeto transcendente ${ }^{40}$.

E, ainda,

[...] uma consciência pura é um absoluto muito simplesmente porque é consciência dela mesma. Ela permanece, portanto, um "fenômeno" no sentido muito particular em que "ser" e "aparecer" são apenas um. Toda ela é ligeireza, toda ela é translucidez. É nisso que o Cogito de Husserl difere do Cogito cartesiano. Mas se o Eu é uma estrutura necessária da consciência, esse Eu opaco é, de um mesmo lance, elevado ao nível de um absoluto. Eis-nos, portanto, na presença de uma mónoda. E é precisamente essa, infelizmente, a orientação do novo pensamento de Husserl [...]. A consciência tornou-se pesada, ela perdeu esse carácter que fazia dela o existente absoluto à força de inexistência. Ela é pesada e ponderável. Todos os resultados da fenomenologia ameaçam entrar em ruína se o Eu não é, do mesmo modo que o mundo, um existente relativo, quer dizer, um objeto para a consciência ${ }^{41}$.

Acompanhando a discussão de Sartre em relação às críticas dirigidas aos filósofos alemães, para Kant, o Eu Puro fora compreendido como uma necessidade/presença formal, como uma condição de possibilidade da experiência e, para Husserl, o Eu era condição de fato da ocorrência da consciência de maneira que a sua tese também aponta para um Eu

\footnotetext{
40 SARTRE, J. P. A transcendência do Ego seguido de Consciência de si e conhecimento de si. Tradução de Pedro M. S. Alves. Lisboa: Colibri, 1994. p. 48.

${ }^{41}$ SARTRE, J. P. A transcendência do Ego seguido de Consciência de si e conhecimento de si. Tradução de Pedro M. S. Alves. Lisboa: Colibri, 1994. p. 49.
} 
transcendental, que estaria por detrás de cada consciência. Percebemos, entretanto, que o que Sartre indica como oposição aos filósofos alemães é o fato de que o "Eu não é nunca puramente formal, que ele é sempre, mesmo abstractamente concebido, uma contracção infinita do Eu (Moi) material"42.

Sartre, uma vez decidido a refutar a fenomenologia husserliana, dedicou-se, ao longo de seu artigo intitulado $A$ Transcendência do Ego (1994), ao desenvolvimento de uma fenomenologia do Ego, a fim de esclarecer os mal-entendidos conceituais acerca da constituição do ego e da consciência. É o que passaremos em revista, agora.

\section{APRESENTAÇÃO DA TRANSCENDÊNCIA DO EGO E DA INTENCIONALIDADE DA CONSCIÊNCIA}

A recusa de Sartre em relação às teses de Kant e de Husserl faz com que ele se pergunte: "Há lugar para um Eu numa tal consciência? "43. A resposta é clara: - Evidentemente não há. Para Sartre, o Ego (Eu) não está em nenhum lugar (dentro) do homem, muito pelo contrário, o "Ego não é proprietário da consciência44", ele está (fora) do homem, logo, está no mundo!

O Ego é um existente, é um objeto transcendente do ato reflexivo ou, se se quiser, um objeto do mundo, como qualquer outro. Nas palavras de Barata, “[...] com efeito, não basta afirmar que o Ego não está na consciência, mas que não está nem formal nem materialmente"45 nela.

Vejamos a posição literal de Sartre nas primeiras páginas da obra $A$ Transcendência do Ego (1994) ${ }^{46}$ :

\footnotetext{
42 SARTRE, J. P. A transcendência do Ego seguido de Consciência de si e conhecimento de si. Tradução de Pedro M. S. Alves. Lisboa: Colibri, 1994. p. 55.

43 SARTRE, J. P. A transcendência do Ego seguido de Consciência de si e conhecimento de si. Tradução de Pedro M. S. Alves. Lisboa: Colibri, 1994. p. 48.

44 SARTRE, J. P. A transcendência do Ego seguido de Consciência de si e conhecimento de si. Tradução de Pedro M. S. Alves. Lisboa: Colibri, 1994. p. 78.

45 BARATA, A. Metáforas da consciência: da ontologia espetacular de Jean-Paul Sartre a uma metafísica da ressonância. Porto: Campos das Letras, 2000. p. 15.

46 SARTRE, J. P. A transcendência do Ego seguido de Consciência de si e conhecimento de si. Tradução de Pedro M. S. Alves. Lisboa: Colibri, 1994. p. 43.
} 
Para a maior parte dos filósofos, o Ego é um "habitante" da consciência. Alguns afirmam sua presença formal no seio das "Erlebnissen" como um princípio vazio de unificação. Outros psicólogos - na maior parte - pensam descobrir sua presença material como centro dos desejos e dos actos em cada momento da nossa vida psíquica. Nós queremos mostrar aqui que o Ego não está na consciência nem formal nem materialmente: ele está fora, no mundo; é um ser do mundo, tal como o Ego de outrem.

Em última análise, o que Sartre quer dizer nas primeiras páginas de seu escrito é que ele rejeita a forma como respondem, tanto a filosofia quanto a psicologia, acerca da dimensão da subjetividade. Melhor contextualizando, trata-se de reconhecer o modo como ambas as disciplinas compreendem a questão do ego e da consciência.

Para Sartre, tanto a filosofia quanto a psicologia concebem a noção do ego como habitante da consciência, agindo, pois, como se a consciência 'não' fosse um fluxo, um para fora, para o mundo. Sabemos que ser consciente de algo é estar diante da presença concreta do que não é a consciência. Logo, para ele, não faz sentido explicar a consciência tal qual a filosofia e a psicologia clássica a concebem. Noutras palavras, em sentido radicalmente fenomenológico, inexiste ego no interior da consciência; inexiste, portanto, qualquer conteúdo, seja ele ôntico ou formal, na consciência, uma vez que todo conteúdo está fora, no objeto. Nessa medida, em síntese, Sartre observa que não há necessidade de um ego transcendental como unificador dos conteúdos da consciência.

Sendo o ego um objeto transcendente, aparecendo como qualquer outro objeto aparece no-mundo, pelo ato da reflexão, esse ego não pode ser unificador da consciência, tampouco do mundo. Assim, em vez de um ego transcendental, o que há é um movimento de "transcendência do ego". Como bem observa Barata, pensar o ego "[...] como transcendente significa pensá-lo em relação a algo que transcende, que não é imanente, 
em relação ao que permanece fora e não dentro"47. Logo, em Sartre, o ego não pode ser idêntico à consciência, tampouco imanente a ela.

Em virtude disso, emerge a questão: - O que constitui a unidade da consciência?

A resposta dessa emblemática questão é, segundo Sartre, o objeto (noema), pois, para ele, o homem, como sujeito sócio-histórico e dialético, está submergido no mundo dos objetos. Assim, portanto, são os objetos que constituem a unidade da consciência: "[...] o objeto é transcendente às consciências que o apreendem e é nele que se encontra a sua unida$\mathrm{de}^{\mathrm{n} 48}$. Para tanto, podemos dizer que o ego, enquanto objeto, é visado pela consciência ou, conforme as palavras de Silva,

[...] se há alguma unidade das consciências que tenho do mundo, esta se encontrará muito mais do lado do objeto do que do lado da consciência. Se os objetos fossem conteúdos da consciência (da representação), então seria necessário um princípio unificador para dar conta da diversidade das operações e das consciências operantes. Mas a fenomenologia mostrou justamente que a consciência não assimila o objeto; pelo contrário, ela sai de si para ir ao encontro do objeto, ela se transcende para encontrar o objeto transcendente ${ }^{49}$.

Quando Sartre almejou desenvolver uma investigação acerca da consciência, como caráter fundamental de sua ontologia, ele o fez partindo da noção de intencionalidade de Husserl. Vale ressaltar que, conforme ele, a in-

47 BARATA, A. Metáforas da consciência: da ontologia espetacular de Jean-Paul Sartre a uma metafísica da ressonância. Porto: Campos das Letras, 2000. p. 14.

48 SARTRE, J. P. A transcendência do Ego seguido de Consciência de si e conhecimento de si. Tradução de Pedro M. S. Alves. Lisboa: Colibri, 1994. p. 47.

49 SILVA, F. L. Ética e literatura em Sartre: ensaios introdutórios. São Paulo: UNESP, 2004. p. 38. 
tencionalidade não é apenas um aspecto da consciência como era em Husserl. Para o fenomenólogo francês, a intencionalidade é a própria consciência ${ }^{50}$. As asserções de Sartre comportam, sem dúvida, uma radicalidade sui generis. Elas aparecem em seu pequeno, porém belíssimo, texto introdutório acerca da teoria husserliana da intencionalidade, intitulado Uma Idéia Fundamental da Fenomenologia de Husserl: a intencionalidade (1947/2005). Nesse primoroso ensaio, Sartre, em poucas palavras, explica o que é a teoria husserliana da intencionalidade. Inicia opondo a fenomenologia husserliana ao que ele denominou de "filosofia alimentar", descrevendo:

"Ele comia com os olhos". Essa frase e muitos outros signos marcam bem a ilusão comum ao realismo e ao idealismo, segundo a qual conhecer é comer. Após cem anos de academicismo, a filosofia francesa ainda não saiu disso. Todos nós líamos [Léon] Brunschvicg, [André] Lalande e [Émile] Meyerson, todos acreditávamos que o Espírito-Aranha atraía as coisas para sua teia, cobria-as com uma baba branca e lentamente as deglutia, reduzindo-as à sua própria substância. O que é uma mesa, um rochedo, uma casa? Um certo composto de "conteúdos de consciência", uma ordem desses conteúdos. Ó filosofia alimentar! ${ }^{51}$

Podemos, entretanto, compreender que a crítica feita por Sartre à "filosofia alimentar" francesa tinha, única e exclusivamente, a intenção de referendar a sua admiração para aquilo que Husserl já fazia em sua teoria acerca da intencionalidade. Ora, “[...] por intencionalidade entendíamos aquela propriedade dos vividos, quer dizer, de 'ser consciência de algo'”52.

50 LAPOINTE, F. H. "Psicología fenomenológica de Husserl y Sartre". In: Revista Latinoamericana de Psicología, Bogotá, v. 2, n. 3, 1970, p. 377-385. Disponível em: http://www.redalyc.org/ pdf/805/80502306.pdf. Acesso em: 10 de setembro de 2018.

51 SARTRE, J. P. Uma idéia fundamental da fenomenologia de Husserl: a intencionalidade. In: . Situações, I: críticas literárias. Tradução de Cristina Prado. São Paulo: Cosac Naify, 2005. p. 29.

52 HUSSERL, E. Idéias para uma fenomenologia pura e para uma filosofia fenomenológica: introdução geral à fenomenologia pura. Tradução de Márcio Suzuki. Aparecida do Norte: Idéias \& Letras, 2006. p. 190. 
De igual forma, "[...] contra a filosofia digestiva do empiriocriticismo, do neokantismo, contra todo o 'psicologismo', Husserl não se cansa de afirmar que não se pode dissolver as coisas na consciência"53. Também na introdução de seu ensaio ontofenomenológico O Ser e o Nada: ensaio de ontologia fenomenológica (1943/2005) Sartre traz essa questão:

\begin{abstract}
Uma mesa não está na consciência, sequer a título de representação. Uma mesa está no espaço, junto à janela, etc. A existência da mesa, de fato, é um centro de opacidade para a consciência; seria necessário um processo infinito para inventariar o conteúdo total de uma coisa [...] o primeiro passo de uma filosofia deve ser, portanto, expulsar as coisas da consciência e restabelecer a verdadeira relação entre esta e o mundo, a saber, a consciência como consciência posicional do mundo [...] ela esgota-se nessa posição mesma: tudo quanto há de intenção na minha consciência atual está dirigido para o exterior, para a mesa $[. . .]^{54}$.
\end{abstract}

Foi, no entanto, em seu texto introdutório de 1939 que Sartre deixou claro que não há objeto que possa entrar na consciência, muito simplesmente porque não é da mesma natureza que ela. Ora, "[...] vêem esta árvore [...] a vêem no lugar exato em que está: à beira da estrada, em meio à poeira, só e curvada sob o calor, a vinte léguas da costa mediterrânea. Ela não conseguiria entrar em suas consciências, pois não é da mesma natureza que elas" ${ }^{\prime \prime}$.

53 SARTRE, J. P. Uma idéia fundamental da fenomenologia de Husserl: a intencionalidade. In: . Situações, I: críticas literárias. Tradução de Cristina Prado. São Paulo: Cosac Naify, 2005. p. 55.

54 SARTRE, J. P. O ser e o nada: ensaio de ontologia fenomenológica. Tradução de Paulo Perdigão. Petrópolis: Vozes, 2005. p. 22.

55 SARTRE, J. P. Uma idéia fundamental da fenomenologia de Husserl: a intencionalidade. In: . Situações, l: críticas literárias. Tradução de Cristina Prado. São Paulo: Cosac Naify, 2005. p. 55-56. 
Com isso se realça a pergunta: o que é a consciência? Parafraseando Agostinho ${ }^{56}$, podemos dizer que, "[...] se ninguém me perguntar, eu sei; se 0 quiser explicar a quem me fizer a pergunta, já não sei". É sob esse prisma que Morris ${ }^{57}$ nos convida a refletir criticamente sobre o "misterioso e inefável" conceito de consciência em Sartre. Ora, para a comentadora, "há muitos preconceitos intelectuais" que interferem na compreensão desse conceito. Não raro, nós nos referimos à consciência como se ela fosse algo. E não é? Não, para Sartre não é! Assim, Sartre parte criticamente da famosa premissa husserliana de que "[...] toda consciência é consciência de alguma coisa [...]" ou, em outras palavras, “[...] toda consciência 'põe' um objeto, ou que toda consciência é uma consciência 'posicional' ou 'tética' - de um objeto" ${ }^{58}$. Em resumo, o que Sartre quer dizer, em sua tese, de forma mais radical, é que não há o menor conteúdo, tampouco a menor possibilidade de uma interioridade na consciência. Em outras palavras, “[...] significa que não há consciência que não seja posicionamento de um objeto transcendente ou, se preferirmos, que a consciência não tem 'conteúdo' "59.

Diante disso, cabe a questão: - O que podemos fazer para 'romper' com os "preconceitos intelectuais" que comprometem nossa compreensão sobre o fenômeno consciência? Morris sugere que devemos mudar a forma de questionamento, perguntando: "O que é ser/estar consciente?" ou "O que é ser/estar consciente de algo?" em vez de "O que é consciência?" ${ }^{0}$. Desse modo, podemos superar a tentação de pensar a consciência como uma coisa, isto é, de reificá-la.

O conceito de consciência em A Transcendência do Ego é transcendental, sem sujeito, logo, impessoal. Vejamos nas palavras do próprio Sartre: é

\footnotetext{
${ }^{56}$ AGOSTINHO, S. Confissões. Tradução de J. Oliveira Santos e A. Ambrósio de Pina. São Paulo: Abril Cultural, 1980. p. 265.

57 MORRIS, K. J. Sartre. Tradução de Edgar da Rocha Marques. Porto Alegre: Artmed, 2009. p. 83.

58 MORRIS, K. J. Sartre. Tradução de Edgar da Rocha Marques. Porto Alegre: Artmed, 2009. p. 83.

59 SARTRE, J. P. O ser e o nada: ensaio de ontologia fenomenológica. Tradução de Paulo Perdigão. Petrópolis: Vozes, 2005. p. 22.

60 MORRIS, K. J. Sartre. Tradução de Edgar da Rocha Marques. Porto Alegre: Artmed, 2009. p. 83.
} 
"pré-pessoal”, não tem Eu [...] "o Eu só aparece ao nível da humanidade ${ }^{61 " .}$ Eis aqui, a originalidade, bem como a radicalidade da noção de consciência, qual seja: a retirada do Ego transcendental e toda a ideia da existência de um sujeito psicológico, interiorizado ou substancial. Ora, o filósofo francês deixa o "campo transcendental" limpo, sem Eu.

O que Sartre quer dizer com campo transcendental? Tal expressão é utilizada pelo filósofo para indicar que existe uma cisão entre a consciência e o Ego, o que implica dizer que a consciência é constituinte e o Ego constituído. Franklin Leopoldo ${ }^{62}$ observa, contudo, que, "em Husserl, isso constitui um problema":

Nas "Investigações Lógicas" Husserl havia concebido o Eu como uma "produção sintética e transcendente da consciência"; nas "Ideias" ele concebe um Eu transcendental como estrutura necessária anterior a cada consciência. Seria o Eu puro que resiste à redução", que permanece idêntico e que não pode ser considerado no mesmo plano do vivido, mas deve ser visto como dado fenomenológico. Sartre interpreta a posição de Husserl como uma duplicação transcendental do Eu psíquico, procedimento que ele considera desnecessário e um retrocesso em relação à concepção anterior de consciência transcendental. ${ }^{63}$

Entender a noção de campo transcendental em A Transcendência do Ego é fundamental para que possamos compreender a realidade humana, pois se o ser humano é o único 'animal' que pode ter consciência de ser

61 SARTRE, J. P. A transcendência do Ego seguido de Consciência de si e conhecimento de si. Tradução de Pedro M. S. Alves. Lisboa: Colibri, 1994. p. 46.

62 SILVA, F. L. "A transcendência do Ego: subjetividade e narrabilidade em Sartre". In: Síntese, Belo Horizonte, v. 27, n. 88, p. 165-182, 2000, p. 169. Disponível em: http://www.faje.edu.br/ periodicos/index.php/Sintese/article/view/742. Acesso em: 05 de junho de 2019.

63 SILVA, F. L. "A transcendência do Ego: subjetividade e narrabilidade em Sartre". In: Síntese, Belo Horizonte, v. 27, n. 88, p. 165-182, 2000, p. 169. Disponível em: http://www.faje.edu.br/ periodicos/index.php/Sintese/article/view/742. Acesso em: 05 de junho de 2019. 
consciente, isso implica dizer que os seres humanos "[...] são capazes de serem conscientes de ... ou que ... [...] $]^{64 "}$. Pois bem: Isso só acontece porque "[...] a intencionalidade nos faz entender que a consciência é de si na medida em que é consciência de um objeto que a transcende"65.

Se a consciência se dá em ato, como bem descreve Schneider, um "estouro para o mundo", como apontou Husserl, logo, "[...] a consciência não é possível antes de ser. Ela só é na medida em que existe: "[...] é, assim, uma plenitude de existência, posto que só existe na medida em que aparece" ${ }^{\prime \prime 6}$. É desse modo que se estabelece a relação fundamental entre a consciência e o mundo: "A consciência e o mundo" - escreve Sartre - "são dados de uma só vez: por essência exterior à consciência, o mundo é, por essência, relativo a ela. É que Husserl vê na consciência um fato irredutível que nenhuma imagem física pode exprimir, a não ser, talvez, a imagem rápida e obscura da explosão"67. Nesse sentido é que a fenomenologia-existencial sartriana afirma que o conhecimento é o resultado da relação entre a consciência e o mundo, isto é, um movimento de "explosão para" ou, ainda, um "[...] arrancar-se do solo seguro do sujeito e pôr-se lá fora, junto das coisas, no mundo"68, observa Conceição:

[...] de um só golpe a consciência está purificada [...] clara como a ventania [...] não há mais nada nela a não ser um movimento para fugir de si, um deslizar para fora de si; se, por impossível, vocês entrassem "dentro" de uma consciência seriam tomados por um turbilhão e repelidos para, para perto da árvore, em plena poeira, pois a consciência não

\footnotetext{
${ }_{64}$ MORRIS, K. J. Sartre. Tradução de Edgar da Rocha Marques. Porto Alegre: Artmed, 2009. p. 83.

65 SILVA, F. L. Ética e literatura em Sartre: ensaios introdutórios. São Paulo: UNESP, 2004. p. 39.

66 SCHNEIDER, D. R. Sartre e a psicologia clínica. Florianópolis: UFSC, 2011. p. 87.

${ }_{67}$ SARTRE, J. P. Uma idéia fundamental da fenomenologia de Husserl: a intencionalidade. In: Situações, I: críticas literárias. Tradução de Cristina Prado. São Paulo: Cosac Naify, 2005. p. 56.

${ }^{68}$ CONCEIÇÃO, A. A tese de Sartre sobre a transcendência do ego: a recepção crítica do método fenomenológico e as origens da ontologia fenomenológica. In: CASTRO, F. C. L.; NORBERTO, M. (Orgs.). Sartre hoje. Porto Alegre, RS: Editora Fi, 2017. p. 257. v. 1. Disponível em: https:// www.editorafi.org. Acesso em: 15 de setembro de 2018.
} 
tem "interior"; ela não é nada senão o exterior de si mesma, e é essa fuga absoluta, essa recusa de ser substância, que a constitui como uma consciência ${ }^{69}$.

Com a noção de intencionalidade como fundamento último da consciência, reconhece Sartre, "Husserl reinstalou o horror e o encanto nas coisas. Ele nos restituiu um mundo dos artistas e dos poetas: assustador, hostil, perigoso [...] ele limpou o terreno para um novo tratado [...] eis-nos libertados de uma 'vida interior'"'70.

Desse modo, se, para Sartre, o Ego é constituído pela consciência (constituinte), já “[...] tudo está fora, tudo, até nós mesmos: fora, no mundo, entre os outros [...]". Se assim é, então cabe interrogar: - Onde nos descobriremos? Nós nos descobrimos "[...] na estrada, na cidade, no meio da multidão, coisa entre as coisas, homem entre os homens"71. Eis, portanto, aqui o motivo pelo qual, em sua filosofia, o ego é transcendente e não transcendental.

\section{CONSIDERAÇÕES FINAIS}

Com o intento de responder à questão que emergiu nos primeiros passos deste nosso estudo, questão que busca compreender o ego nos fundamentos da filosofia sartriana como um ego transcendente e não transcendental, podemos considerar que, quando Sartre parte do princípio husserliano de intencionalidade, apontando que a consciência precisa do objeto para existir, a consciência passa a ser fenomenologicamente descrita como um deslizamento, um movimento de explosão. Essa metáfora apenas evoca uma resistência, no sentido de a consciência resistir a

69 SARTRE, J. P. Uma idéia fundamental da fenomenologia de Husserl: a intencionalidade. In: Situações, I: críticas literárias. Tradução de Cristina Prado. São Paulo: Cosac Naify, 2005. p. 56.

70 SARTRE, J. P. Uma idéia fundamental da fenomenologia de Husserl: a intencionalidade. In: Situações, I: críticas literárias. Tradução de Cristina Prado. São Paulo: Cosac Naify, 2005. p. 57.

71 SARTRE, J. P. Uma idéia fundamental da fenomenologia de Husserl: a intencionalidade. In: Situações, I: críticas literárias. Tradução de Cristina Prado. São Paulo: Cosac Naify, 2005. p. 57. 
tornar-se um ser substancial, pois sentimentos, significações e o próprio ego não aparecem como mera soma de reações subjetivas. Logo, são todos atos intencionais dirigidos ao mundo pela consciência, que parte de e em direção às coisas, que podem ser reais ou imaginárias.

Dessa forma, a transcendência, no discurso sartriano, não tem nenhum significado metafísico ou espiritual, mas, sim, tem a ver com a intencionalidade pela qual o ego é lançado para fora e, portanto, descrito pela consciência como um objeto do e no mundo.

\section{REFERÊNCIAS}

AGOSTINHO, S. Confissões. Tradução de J. Oliveira Santos e A. Ambrósio de Pina. São Paulo: Abril Cultural, 1980.

ALVES, P. Irrefletido e reflexão: observações sobre uma tese de Sartre. In: SARTRE, J. P. A transcendência do ego seguido de Consciência de si e conhecimento de si. Tradução de Pedro M. S. Alves. Lisboa: Colibri, 1994. p. 7-41. https://doi.org/10.11606/issn.2447-9012.espinosa.2013.81261

BARATA, A. Metáforas da consciência: da ontologia espetacular de Jean-Paul Sartre a uma metafísica da ressonância. Porto: Campos das Letras, 2000.

CONCEIÇÃO, A. A tese de Sartre sobre a transcendência do ego: a recepção crítica do método fenomenológico e as origens da ontologia fenomenológica. In: CASTRO, F. C. L.; NORBERTO, M. (org.). Sartre hoje. Porto Alegre: Editora Fi, 2017. p. 253- 275. v. 1. Disponível em: https://www.editorafi.org. Acesso em: 15 set. 2018. https://doi.org/10.11606/d.8.2009.tde-08022010-160422

COOREBYTER, V. Sartre face à la phénoménologie: autour de "L'Intentionnalité» et de "La transcendence de l'Ego". Bruxelles: Ousia, 2000.

HOFFE, O. Immanuel Kant. Tradução de Christian Viktor Hammm e Valério Rohden. São Paulo: Martins Fontes, 2005.

HUSSERL, E. Idéias para uma fenomenologia pura e para uma filosofia fenomenológica: introdução geral à fenomenologia pura. Tradução de Márcio Suzuki. Aparecida do Norte: Idéias \& Letras, 2006. https://doi.org/10.11606/ issn.2318-9800.voi1op141-146

KANT, I. Crítica da razão pura. Tradução de Manuela Pinto dos Santos. Lisboa: Fundação Calouste Gulbenkian, 2001. p. 157-158; B 132. Versão em 
PDF disponível em: http://www.verlaine.pro.br/estetica/critica_da_razao_pura.pdf. Acesso em: 8 ago. 2018. https://doi.org/10.11606/d.8.2013. tde-22102013-100358

LAPOINTE, F. H. Psicología fenomenológica de Husserl y Sartre. Revista Latinoamericana de Psicología, Bogotá, v. 2, n. 3, 1970, p. 377-385. Disponível em: http://www.redalyc.org/pdf/805/80502306.pdf. Acesso em: 10 set. 2018. MORRIS, K. J. Sartre. Tradução de Edgar da Rocha Marques. Porto Alegre: Artmed, 2009.

PRIEST, S. The subject in question: Sartre's critique of Husserl in The transcendence of the ego. London/New York: Routledge, 2000.

SARTRE, J. P. A transcendência do ego seguido de Consciência de si e conhecimento de si. Tradução de Pedro M. S. Alves. Lisboa: Colibri, 1994.

SARTRE, J. P. Uma idéia fundamental da fenomenologia de Husserl: a intencionalidade. In: SARTRE, J. P. Situações, I: críticas literárias. Tradução de Cristina Prado. São Paulo: Cosac Naify, 2005.

SARTRE, J. P. O ser e o nada: ensaio de ontologia fenomenológica. Tradução de Paulo Perdigão. Petrópolis: Vozes, 2005.

SASS, S. D. A concepção sartriana de ego transcendental. Educação e Filosofia, Uberlândia, v. 13, n. 26, p. 263-274, jul./dez. 1999. p. 266. Disponível em: http://www.seer.ufu.br/index.php/EducacaoFilosofia/article/view/779. Acesso em: 12 set. 2018.

SCHNEIDER, D. R. Sartre e a psicologia clínica. Florianópolis: UFSC, 2011.

SILVA, F. L. A transcendência do ego: subjetividade e narrabilidade em Sartre. Síntese, Belo Horizonte, v. 27, n. 88, p. 165-182, 2000. Disponível em: http:// www.faje.edu.br/periodicos/index.php/Sintese/article/view/742. Acesso em: 5 jun. 2019. https://doi.org/10.20911/21769389v27n88p165-182/2000 SILVA, F. L. Ética e literatura em Sartre: ensaios introdutórios. São Paulo: UNESP, 2004.

\section{ENDEREÇO CORRESPONDÊNCIA:}

Reitoria. R. Universitária, 1619 - Universitário. Cascavel - PR - Brasil. CEP: 85819-110. 